Momčilo D. Savić

$C D U$ 801.559.13/.15(497)

Beograd

\title{
L'ESPRESSIONE DEL PASSATO NEI QUOTIDIANI DELLE LINGUE BALCANICHE*
}

E inutile sottolineare che le lingue pariate dai popoli della Penisola balcanica vanno d'accordo in molti punti, pur non avendo la stessa origine. Le affinità in questione sono dovute tanto alla simbiosi quanto alla convivenza prolungatasi a un periodo plurisecolare. Però se non è sempre possibile determinare $i$ confini etnici di un popolo balcanico (cosa che trova riscontro anche altrove), non è neanche meno facile segnarne i rispettivi limiti linguistici. Senza dubbio, possiamo supporre che la situazione in questo campo fosse molto più complicata nei secoli scorsi, essendosi costituite le nazioni vere e proprie appena con le rivoluzioni borghesi, e specialmente se ricordiamo che in certe zone dei Balcani continuano ad essere applicate più lingue e che vi incontriamo oggi stesso un numero non insignificante di persone bilingui ovvero plurilingui. ${ }^{x}$

$\mathrm{E}$ tenendo conto di questo momento vorremmo esaminare come venga espresso il tempo passato, una categoria temporale indispensabile dal punto di vista logico, nei linguaggi dei popoli balcanici. ${ }^{2}$ Siccome è difficile, però, individuare i linguaggi vivi, essendo quasi sempre incoglibili ed indefinibili, dato che tutte le lingue balcaniche (il che vale anche parlando di lingua in generale) posseggono più dialetti (per non discuterne delle parlate di cui abbiamo a disposizione scarse descrizioni complete, il che - se anche non ci mancasse - esigerebbe, a sua volta, uno spazio che superasse di gran lunga le poche pagine di un contributo sintattico-stilistico come il nostro), abbiamo deciso di ravvisare il problema di cui ci interessiamo alla lingua dei quotidiani, consci della quasi impossibilità di trovare un cođice rappresentativo su cui esaminare le dette lingue e convinti che il linguaggio giornalistico, destinato ad informare i ceti più larghi della popolazione, sia davvero un mezzo di comunicazione accessibile a tutti quelli che si servono della lingua rispettiva ovvero dei suoi dialetti o delle parlate.

Nello stesso tempo riteniamo che in questo modo abbiamo intavolato la discussione sulla comunicazione vera e propria, e non sull'espressione affettiva qual'è per 1o più il linguaggio quotidiano, il che vuol dire che le nostre ricerche si ristringono a determinate pagine dei gionnali.

Rileviamo subito che il nostro lavoro è limitato all'esame di quei tempi verbali dell'indicativo che rispecchiano la categoria del passato, quella cioè del preterito del presente, e non all'esame di quei mezzi temporali che servono ad esprimere il preterito del passato, cioè il piuccheperfetto. ${ }^{3}$ Sottolineiamo 
ancora che non abbiamo compreso in queste pagine cosiddette forme pluricomposte (in francese «formes surcomposées» del tipo j’ai eu fait), le quali, sebbene di rado, fanno parte dei quotidiani pubblicati nelle lingue balcaniche, benché questi tempi spettino piuttosto alla categoria del passato che a quella del preterito del passato (il che resta discutibile)."

Passando al punto essenziale del presente lavoro dobbiamo mettere in rilievo che il nostro interesse è rivolto - in primo luogo - a esaminare come si comportino le lingue balcaniche riguardo al problema dell'espressione sintetica ed analitica relativa al passato. " Trattandosi però di un problema complesso, legato a lingue di varia origine slava, romanza ed altra), e non avendo la possibilità d'intavolare in questa sede una discussione approfondita, dovremo evitare una premessa a parer nostro importantissima: se cioè nelle forme verbali la funzione delle quali è argomento del nostro lavoro abbiamo da fare col «passato» o col «preterito» o con qualcosa d'altro, visto che, p. es., la maggior parte delle lingue balcaniche (non tutte) adopera, oltre al termine proprio, anche l'appellativo d'aoristo per indicare iI perfetto (passato) semplice.

Questo fatto, da un lato, nonché il tempo limitato a pochi minuti, dall'altro, ci hanno spinto a tralasciare l'uso dei termini adoperati da ciascuna delle lingue balcaniche per le forme temporali in parola, pur sapendo che la terminologia esistente non si riduce mai a etichetta ma segna qualche volta anche il valore funzionale. "Il problema, però, l'abbiamo risolto ricorrendo a una terminologia abbastanza semplificata, formata in base ai termini messi in uso dalle grammatiche francesi (imparfait, passé simple, passé composé), con poche modifiche, sperando che le denominazioni, pur essendo artificiali, siano comprensibili a tutti. Applicheremo, dunque, i seguenti termini: l'imperfetto, il passato semplice e il passato analitico (e quest'ultimo sottolinea molto bene la sostanza della nostra indagine).

Volendo prendere in esame come si rispecchia il problema in questione sui quotidiani delle lingue balcaniche, abbiamo tentato di giovarci degli esempi di ciascuna delle dette lingue sfruttandone brani tipici dai giornali pubblicati nelle capitali dei rispettivi Paesi. Anche se, forse, sarebbe stato più giusto cominciare l'esame col greco, la cui tradizione antichissima supera di gran lunga tutte le altre lingue dei Balcani, noi abbiamo preferito proseguire nel senso opposto e, andando da nord a sud, abbiamo cominciato col romeno ed il serbocroato per passare poi al bulgaro, al macedone e all'albanese per concludere, infine, col greco. Quanto all'ungherese e lo sloveno, non li abbiamo inclusi nelle nostre ricerche, ritenendo che si tratti delle lingue che difficilmente si inquadrano fra quelle balcaniche, almeno dal punto di vista del problema di cui ci occupiamo. ${ }^{7} \mathrm{Ma}$ ci siamo giovati del turco, pur avendo da fare con una lingua non indoeuropea, che possiede le forme verbali sintetiche, tanto differenti da quelle delle lingue europee. ${ }^{8}$ Questo fatto, però, giustifichiamo col dire che il sistema verbale turco, che esprime il tempo passato ora con le forme terminanti in -di ora con quelle terminanti in -miş, non è restato senza influenza su alcune lingue balcaniche, p. es., il bulgaro, il macedone, parzialmente l'albanese e, forse, anche qualche dialetto serbocroato. 
Trattando il problema di come viene espresso il passato nei quotidiani pubblicati nelle lingue balcaniche, dovremo occuparci del problema di ciascuna singola lingua, e dire che non escludiamo che le conclusioni a cui perverremo non potranno essere che parzialmente inquadrate nelle norme e nelle regole date dagli specialisti di ogni lingua balcanica, che anzi che appariranno sbagliate se non saranno esaminate nell'ambito di un comune quadro balcanico. In fine, siamo convinti che il nostro metodo sarà di qualche utilità a coloro che si assumono la fatica della compilazione delle grammatiche normative delle dette lingue, trascurando l'influenza delle lingue limitrofe.

Passando ai testi diremo che per il romeno abbiamo sfruttaito la Scînteia, ${ }^{10}$ per il serbocroato abbiamo applicato la Политика, ${ }^{11}$ per il bulgaro abbiamo avuto a disposizione il Работннческо дело,"2 per il macedone, la Нова Македонија, ${ }^{13}$ per l'albanese, lo Zëri i popullit, ${ }^{14}$ e per il greco ci siamo giovati tanto

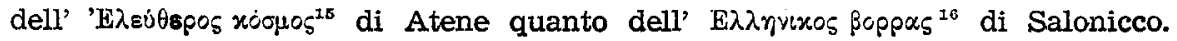
Per il turco abbiamo spigolato gli esempi dal Cumhuriyet. ${ }^{17}$

Ma prima di porgere brani interi, pieni d'esempi significativi, offertici dai detti quotidiani, è necessario rilevare che quello che intenzionavamo convalidare risulta chiaro a prima vista gettando uno sguardo superficiale ai titoli che vi si riscontrano. Così, sulla Scînteia (p.1) troviamo il titolo: «Judeţul Bacău a îndeplinit planul pe primij trei ani ai cincinatului ['La provincia di Bacau ha compiuto i primi tre anni del piano quinquennalè $\left.{ }^{18}\right]$ », e sulla Политика (p. 14) si legge: «Срећан што је остао жив ['felice perchè è restato vivo']», donde risulta che ambedue i quotidiani applicano il passato analitico. Un quadro dissimile ci offrono i quotidiani delle altre lingue balcaniche. Così, sul Работническо дело (p. 2), c’imbattiamo nel titolo: «Югославският гост отпътува ['L'ospite jugoslavo se ne parti']». La stessa forma verbale s'incontra sulla Нова Македонија (р. 1): «Садат го прими југословенскнот амбасадор Јаворски ['Sadat accolse l'ambasciatore jugoslavo Javorski']», nonché sullo Zëri i popullit (p. 1): «Rrethi i Shkodrës plotësoi planin e prodhimit të përgjithshëm industrial të 8-mujerit ['La provincia di Scutari compi il piano della produzione generale di otto mesi']». Una forma corrispondente troviamo anche

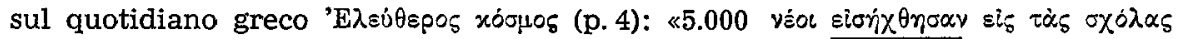

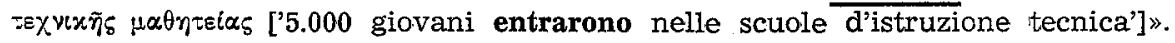
II giornale turco Cumhuriyet offre le forme che abbiamo aspettate (p. 1): «Erbakan, Kıbrıs'ta yeni bir statü kurulacağın acıkladı ['Erkaban dichiarò che a Cipro sarebbe arrivato a una nuova situazione']».

Comunque, in base ai titoli spigolati dai giornali menzionati, possiamo affermare che i quotidiani romeni e serbocroati vi applicano la forma analitica, quelli bulgari, macedoni, albanesi e greci, invece, ricorrono alla forma sintetica. Quanto ai giornali turchi, in questa applicazione non vi incontriamo che le forme terminanti in - di.

Cominciando col romeno dimostreremo, citando un brano pubblicato sotto il titolo Vizitele delegatiei parlamentare engleze ['Le visite della delegazione 
parlamentare inglese'] (p. 7), che la lingua giornalistica in questione si serve quasi esclusivamente del passato analitico: ${ }^{10}$

In continuarea vizitei pe care o interprinde in țara noastră, delegația de parlamentari englezi, condusă de Sir Fitzroy Maclean, menabru al Camerei Comunelor, a fost ['è stata'] vineri oaspetele județului Bihor.

Oaspeții englezi au vizitat ['hanno visitato'] Institutul județean de proiectări al Consiliului popular Bihor.

În cursul aceleiaşi zile, parlamentarii englezi au vizitat ['hanno visitato'] spitalul de copii, fabrica de mobilă «Alfa», fabrica de incălțăminte "Solidaritatea», noul cartier de locuințe din zona de vest și stațiunea Băile Felix.

In cinstea oaspeților, preşedintele consiliului popular județean Petre Blajovici a oferit ['ha offerto'] un dineu în saloanele restaurantului «Transilvania» din Oradea.

Un altro articolo, intitolato Simbolurile noului de la Visonta ['I simboli del nuovo di Visonta'] (p. 7), ci fa evidente la possibilità del romeno di applicare l'imperfetto nella lingua dei quotidiani per indicare un'azione iterativa, il che è una funzione tradizionale di questo tempo: $:^{20}$

Am vizitat ['ho visitato'] în ultima vreme mai multe localități. Reveneam ['rivenivo'] în ele, după ani de zile, regăsindule... întinerite. ... Una din asezările recent vizitate este Visonta din apropiere de oraşul Gyöngyös. Visonta este un nume şi; totodată, un simbol. Un simbol al dezvoltării energeticii ungare. Aici, la inceputul anului, a intrat ['è entrata'] in funcțiune o termocentrală.

A differenza del romeno che vi si serve del passato analitico ricorrendo di rado all'imperfetto, il serbocroato ha a disposizione esclusivamente il suo passato analitico tanto d'aspetto perfettivo quanto di quello imperfettivo, ${ }^{21}$ come ce 10 può far vedere un articolo dato col titolo Магнетофон у судници l'Il magnetofono nella corte d'assise'] (p. 4):

Jедног дана [жена] је сакрнла ['ha nascosto', pf.] мarнетофон у кухињи, а микрофон поставила ['ha posto', pf.] у спаваћу собу. Када је пред вратима стана чула" ['ha sentito', pf.] мужевљеве коpaкe, укључила је ['ha attaccato', pf.] магнетофон и ушла ['è entrata, pf.] y coбy ...

Све је нзгледало ['è parso', impf..] чнсто и јасно, али судија тиме није био ${ }^{23}$ ['è stato'] задовољан. Упутио је ['ha inviato', pf.] траку, а и оптуженог мужа, на испитивање у специјалну службу команде главне милиције. После неколико дана суд је добио ['ha ricevuto', pf.] извештај који је гласио ['ha sonato', impf.]: На основу извршене фоноскопске експертизе утврђено $\mathrm{je}^{21}$ ['è stato constatato', pf.] да говор мушкарца, регистрован на магнетофонској траци, није глас мужа тужитељке.»

Avendo perduto da tempo l'imperfetto che trova scarsissima applicazione anche nelle opere letterarie, il serbocroato sta per perdere anche il passato semplice (non rifuggendo nella letteratura che a quello d'aspetto perfettivo), che è completamente sparito nei dialetti čakavo e kajkavo e che sta in via di sparizione anche in certe zone del dialetto štokavo. ${ }^{25}$ Quanto ai quotidiani, questo tempo, diventato un mezzo affettivo dal principio del '900 e - diremmo - specialmente in quest'ultimo dopoguerra, vi ricorre di rado, e cioè quando 
il giornalista, tralasciando la comunicazione vera e propria, passa all'espressione letteraria o, qualche volta, come segue dall'articolo intitolato Све, све али умерено ['Tutto, tutto - ma modestamente'] (p. 4), sta completando la proposizione precedente (possibilità non estranea neanche della lingua degli scienziati):

Oн [Гален] је, записа ['notò'] историчар, у Рим стигаo ['è giunto', pf.] из Александрије године 64. ове модерне ере и у Риму је одмах навукао ['si è attirato', pf.] на себе мржњу целе лекарске елите «вечног града».

\section{II}

Passando alle altre lingue balcaniche, vediamo cambiare il sistema d'espressione del passato, cioè vi troviamo la proporzione tra forme analitiche e sintetiche opposta a quella che abbiamo constatata nel quotidiano romeno e quello serbocroato. Dunque, se nella stampa romena e in quella serbocroata l'imperfetto rispettivamente il passato semplice sono di parca applicazione, nei quotidiani delle altre lingue balcaniche questi due tempi funzionano come mezzi principali, specialmente il passato semplice, quell'analitico invece vi si adopera di rado.

Un editoriale del quotidiano bulgaro, intitolato Със эаветите на вожна ['Col voti del duce'] (p. 1); già ne parla in proposito offrendoci a vicenda passati semplici ed imperfetti:

Израсъл сред народа. той [Георги Димитров] посшети ['dedicò'] целия си живот на неговите освободителни борби, на делото на работническата класа, на социалистическите идеали. Под неговото изпитано и мъдро ръководство партиятя направи ['fесе'] и първите си стъпки в работата за изграждането на новия живот ...

Oще в първите години на народната власт то: напомняше ['menzionava'], че се заблуждава всеки, който мисли, че може да направи някое добро дело на своя народ в. борба или неприязън към работническата класа и Комунистическата партия, подчертавawe ['sottolineava'], че новия живот може да се гради само под ръководството на паботническата класа...

Un altro articolo, relativo a una notizia politica, dato col titolo Подробности эа срешата на Л. К. Брежњев с американски журналисти ['Particolarità dell'incontro di L. I. Breznev con i giomalisti americani'] (p. 6), ci offre un unico passato analitico, nel dialogo, riservando alla narrazione il passato semplice: ${ }^{\text {ac }}$

66-годешният генерален секретар на ЦК на ПКСС влезе ['entrd'] в стаята с незапалена цигара в дясната ръка, ръкува се ['strinse la mano'] с вскчки и седна ['si pose a sedere'] от другата страна на дългата маса, срешу журналистите.

«Пренполагам, че никой от нас ня е бил в таэи стая,» каза ['disse'] той. След това обясни ['spiegò'] накратко как работи Политбюро.

In questo riguardo il sistema del giornale macedone va d'accordo con quello precedente. Citiamo i brani di un articolo Влошени либиско-египетски односи ['Peggiorati i rapporti libico-egiziani'] (p. 1), in cui figura un unico passato analitico fra tanti tempi sintetici: 
До денес на пладне, никакво официјално објаснување не можеше ['poteva'] да биде добиено за оваа акција на либиските власти, ниту со било кој од либиските дипломати беше ['era'] можно да се разговара...

Пред извесно време од Трнполи се врати ['tornò'] во Каиро министерот д-р Мурат Галеб кој се наоѓaше ['si trovava'] на должност во либиоскиот главен град од официјалното прокламирање на двојната унија во почеткот на септември. Официјално беше ['еra'] речено дека Галеб дошол ['ѐ arrivato'] «на кратки консултации» спроти одижавањето на алжирскиот самит ... .

Un altro articolo del giornale macedone, apparso sotto il titolo Влаща на славни непознати личности ['Il governo delle celebri persone ignote'] (p. 3), va anche a conferma delle nostre affermazioni: ${ }^{27}$

Маврос исто така изјави ['dichiarò'] дека е задоволен од промената на режимот и истакна ['mise in rilievo'] дека се работело ['si è trattato'] и за соборување на личниот режим иа Георге Пападопулос, бидејќи искуство од минатите шест години покажа ['dimostrò'] дека воената администрација не може ништо да направи.

Маврос потоа стана ['affrontò'] против стопанската политика на бившата влада... Исто така, тој ги критикуваше ['criticava'] инвестищиите без контрола во доменот на туризмот.

Passando dai quotidiani bulgaro e macedone a quello albanese abbiamo l'impressione che non vi si sia cambiato che il fondo lessicale; il sistema d'espressione del passato vi è rimasto identico a quello esistente sui due giornali precedenti. Un brano relativo alla situazione militare del Cambogia, (Fitore të patriotëve camboxhianë ['Vittorie dei patriotti cambogiani'], p. 4.), ce ne dà una valida conferma:"s

Agjensia kamboxhiane e informacionit, dukë bërë bilancin e sulmeve kundër armikut giatë muajit korrik, njofton se forcat clirimtare giatë kësaj periudhe asgjësuan ['annientarono'] 8600 ushtarë të armikut, shkatërruan ['distrussero'] ose dëmtuan ['danneggiarono'] 51 maqina ushtarake, rrëzuan ['abbatterono'l ose goditën ['colpirono'] 12 aeroplanë, mbytën ['affogarono'] ose dëmtuan 「'danneggiarono'] 9 mjete lundrimi. zunë ['ratturarono'] më se 1500 armë dhe materiale të tjera ushtarake. Njoftohet gijtashtu. se forcat e klikës së Lon Nolit kanë pēsuar ['hanno sofferto'] humbje të rënda edhe në Angtasom, Kampong, Trabek.

Le prime frasi di un altro articolo, intitolato Pse ky sentimentalizëm? ['Perché questo sentimentalismo?'] (p. 2), di nuovo ci offrono l'alterarsi a vicenda $i$ due tempi sintetici senza qualsiasi passato analitico:

Një vit më parë në «Zërin e popullit» u botua 「'si pubblicò' n nië articull $\mathrm{ku}$ disa drejtues të Koplicut. të cilët $\mathrm{i}$ ishin kundërvënë rinisë së kooperativës, kritikohshin ['venivano criticati'] për disa cfaqje të tyre konservatore. Midis tyre ishte l'erat edhe krvetari i kooperativës Col Cufi. Ai, duke giykuar nga pozita të shtrembëra bajraktarizmi, nuk paitohej ['si adattava'† me veprimet dhe siellet, revolucionare të rinisë. Mirëpo edhe pas dalies së articullit. orọnizata - bazë e partisë e sektorit të aendrës as që u ndië l'si sentì' fare e giallë. E mbytur nga sentimentalizmi, ajo heshti ['tacque'] para të metave të niohura të krvetarit.

Neanche lo stile giornalistico greco cambia in questo riguardo, ricorrendo ora all'imperfetto ora al passato semplice (aoristo), come risulta da un edito- 


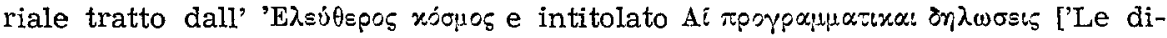
chiarazioni programmatiche'] (p. 1):28

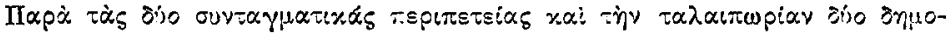

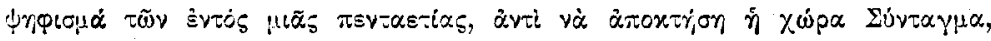

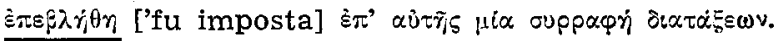

Tó

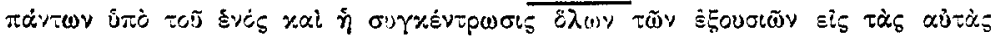

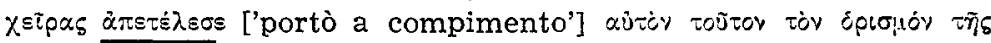
rupavias.

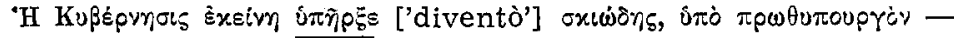

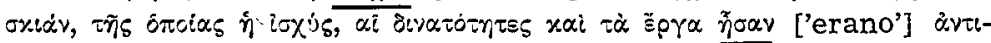

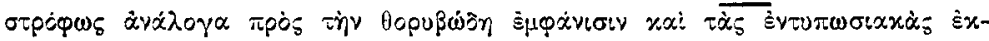

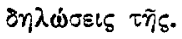

Non abbiamo trovato nessun passato analitico neanche in un articolo re-

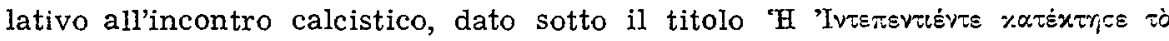

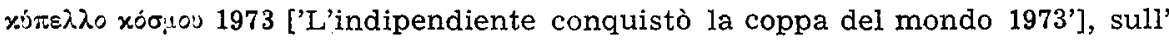

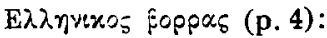

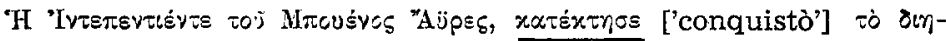

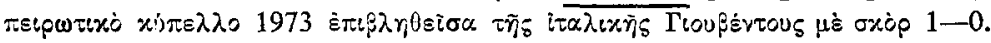

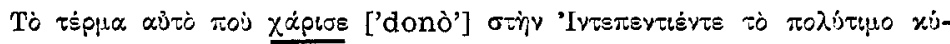

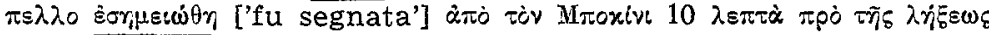

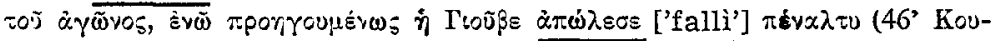

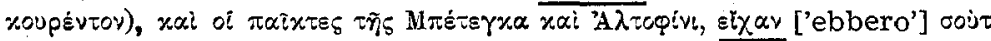
ờ̀ zoxò.

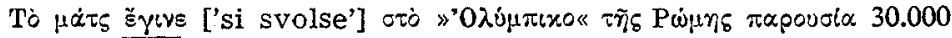

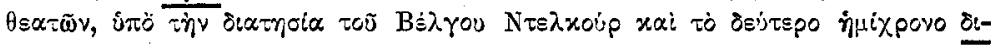

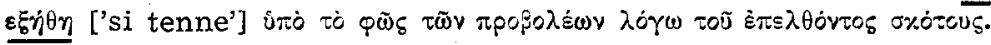

Prendendo in esame lo stile giornalistico turco dobbiamo limitarci dalle ricerche fatte finora nel quadro delle altre lingue balcaniche d'origine indoeuropea. Qui, sottolineiamo, si tratta di una lingua uralo-altaica che non possiede forme verbali analitiche. Perciò il nostro interesse non è rivolto che al sistema d'espressione del passato di questa lingua, dato che il turco - come già dicemmo - irradiava sulle lingue balcaniche per secoli, del che, oltre all'influenza lessicale, è evidente anche quella sintattico-stilistica in alcune lingue letterarie odierne. Giudicando in base ai testi giornalistici, il sistema turco d'espressione del passato è tanto chiaro quanto istruttivo per lo studio delle altre lingue balcaniche in cui ha lasciato qualche traccia. Citiamo, p. es., il titolo Orduya yap:Ian bağışlar 1,5 milyara yaklaştı l'Contribuzioni che si fanno all'armata s'avvicinarono a 1,5 milliardo'] (p. 1) soto cui segue il testo:

Türk Silâhl Kuvvetleri ile Donanma ve Hava Vakıflarına, Kıbrıs barış karekâtin!nı başladığı günden beri sürdürülen yardemlar:n toplamı tüm yurtta 1 milyar 420 bin liray: bulmuștur ['è ammontato']. Bu arada, Genelkurmay Başkanlığı, Basın Yayın ve Halkla Ilişkiler Subesi bir açıklama yaparak, para bağıslar: için bankaların «Silâhlı Kuvvetlere» bağış hesabı eçtı̆̆ın bildirmiştir ['ha comunicato']. 
La differenza funzionale fra i due tempi (il primo abbiamo reso col passato semplice, il secondo con quello composto) si riduce a ciò che il parlante, usando la forma terminante in -di (in turco görülen geçmiş zaman ['tempo passato visto'], ci fa sapere di essere stato testimone oculare delle azioni che espone, e che, al contrario, ricorrendo alla forma terminante in -miş (in turco ögrenilen geçmiş zaman ['tempo passato udito'], ci comunica di esserne stato informato senza evidenza personale. ${ }^{\text {so }}$ Questa differenza funzionale non è mai casuale, al che è dovuto il fatto che dopo un titolo dato con la forma terminante in -di, p. es., ABD'de hava korsanlartna ölüm cezası verilmesini öngören kanun kabul edildi ['Negli Stati Uniti Americani fu accettata la legge che prevede la pena di morte per i pirati aerei'], segue il testo in cui figurano le forme terminanti in -miş (p. 3):

Amerikan Senatosu özel durumlarda hava korsanlarına ölüm cezas: verilmesini öngören bir kanun tasarısın t kabul ettikten sonra, onaylanmak üzere Beyaz Saraya göndermişter ['ha inviato'].

Senato, sözü geçen kanun tasarısını oybirliğiyle kabul etmiṣtir ['ha accettato'].

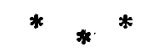

Alla fine, desiderando offrire un quadró riassuntivo dei mezzi in questione, tenendo conto soprattutto del rapporto esistente fra l'espressione sintetica e quella analitica, possiamo pervenire alla seguente conclusione parlando in ambiti generali: sulla base dei tempi indicativi che figurano nei quotidiani contemporanei, le lingue balcaniche possono esser raggrupate in due tipi: al primo appartengono il romeno e il serbocroato, che si giovano del passato analitico (astrazion fatta da scarsissima applicazione d'altri tempi), mentre del secondo fanno parte tutte le altre lingue (eccetto il turco), che ricorrono quasi esclusivamente al passato semplice rispettivamente all'imperfetto applicando eccezionalmente un passato analitico. Il turco, invece, una lingua non indoeuropea e sintetica, sta a parte avvicinandosi al secondo tipo.

Prescindendo da tanti stili delle dette lingue (p. es., quello strettamente letterario, quello scientifico, quello della storiografia, ecc.), che si comportano differentemente a questo riguardo (e che vale la pena di prendere in esame). dovremo avvalerci del detto - che non si riduce che a un'indagine parziale per spiegare la situazione esistente in questo piano.

Tutto quanto abbiamo finora esposto c'induce, però, riportandoci a qualche nostra ricerca anteriormente effettuata in questo senso, a ravvisare il problema fuori da confini meramente balcanici e ad esaminare tanto le influenze irradiate (ed agenti ancora oggi) dall'occidente, quanto quelle orientali che furono presenti per un tempo lunghissimo su un vasto territorio balcanico, non dimenticando l'influsso di un antichissimo sostrato balcanico, dunque, autoctono.

Quest'ultimo elemento è il più efficiente. La forza del sostrato balcanico, riflesso nelle forme sintetiche dell'antichità e conservato nelle forme sintetiche del passato delle lingue greca ed albanese, è stata risentita anche dalle lingue slave dei Balcani. Se ci poniamo la domanda perché mai l'imperfetto e il passato 
semplice (aoristo) siano scomparsi da tutte le lingue slave orientali ed occidentali, la risposta è semplice: la presenza dell'aspetto verbale ha reso superflio l'uso dei due tempi sintetici. Senza dubbio, si tratta della situazione che s'incontrerebbe oggi nei Balcani se non ci fosse stata l'influenza del sostrato, il cui effetto si rispecchia meglio al sudest che al nordovest; da ciò deriva la conservazione delle forme sintetiche nel bulgaro e nel macedone, il loro lento ma sicuro perdersi nel dialetto štokavo della lingua serbocroata e la totale sparizione negli altri due dialetti, kajkavo e čakavo, e, finalmente, la loro assenza nello sloveno (unica lingua slava meridionale che non conosce queste forme, pur essendovene qualche traccia nelle parlate slovene).

Bisogna rilevare poi un'influenza che irradia da un centro europeo eliminando l'espressione sintetica in vaste zone dell'Europa occidentale, centrale ed orientale. La Penisola balcanica non è restata immune da influenze esterne. L'espressione sintetica primordiale vi è stata sostituita da quella analitica. Quanto all'influenza turca a questo riguardo, vi dobbiamo vedere - parlando grosso modo e individuandola in maniera che superi i limiti della lingua bulgara e quella macedone - , un fenomeno secondario, aggiuntovi relativamente tardi a dare un nuovo slancio alle forme sintetiche. ${ }^{31}$

Terminando diremo che la sostituzione delle forme verbali sintetiche con quelle analitiche è in corso anche nei Balcani. Paragonando la Политнка odierna di Belgrado col primo numero di questo giornale, apparso nel lontano 1904, abbiamo constatato a prima vista che il passato semplice vi era indispensabile. $\mathrm{E}$ oso ripetere - in base a un'indagine insufficiente - un 'affermazione simile parlando del romeno. Indagare però questo fenomeno nel piano diacronico sarebbe inutile, essendo il giornalismo di data relativamente recente, specialmente nei Balcani i cui popoli avevano da risolvere per secoli altri problemi più importanti.

\section{NOTE}

* Questo lavoro è stato presentato e discusso al $3^{\circ}$ Congresso di Balcano1 gia, tenuto a Bucarest nel settembre 1974 .

${ }^{I}$ A proposito ci riferiamo alla Linguistique balkanique' di $\mathrm{Kr}$. Sandfeld, riapparsa a Parigi nel 1968 (edizione danese è del 1927 e la prima francese del 1930), le cui pagine sono in parte relative al problema di cui ci occupiamo.

' Cfr. i nostri lavori concernenti i problemi similari delle lingue europee e balcaniche, per lo più individuati dal punto di vista comparativo: Le principali funzioni dell'aoristo serbocroato e del passato remoto italiano (in Linguistica VII/1, Ljubljana 1965, p. 65-71); Osnovne funkcije srpskohrvatskog aorista $i$ rumunskog prostog perfekta $u$ svetlosti romanskih $i$ balkanskih jezika (in Anali Filološkog fakulteta 9, Belgrado 1969, p. 145-211) con un riassunto in italiano intitolato Le principali funzioni dell'aoristo serbocroato e del perfetto semplice romeno alla luce delle lingue romanze e balcaniche (p. 207-211), nonché il testo aggiornato e riveduto, publicato in un volume in lingua romena sotto il titolo Fune, iile de bază ale aoristului sîrbocroat si ale perfectului simplu românesc în lumina limbilor romanice și balcanice, Panciova 1972; Iskazivanje prošlosti u srpskohrvatskoj i rumunskoj publicistici ['L'espressione del passato nella pubblicistica serbocroata e quella romena'] (in Radovi Simpozijuma Actele Simpozionului, Vršac 1970, Pančevo 1971, p. 369-382); Contribu ie la cercetarea comparativă a aoristului sîrbocroat și a perfectului simplu român 
în limba literară ['Contributo allo studio comparativo dell'aoristo serbocroato e del perfetto semplice romeno nella lingua letteraria'] (in Anale ale Societătiii de limba română din PSA Voivodina 1, Zrenjanin 1970, p. 65-74); Sredstva za iskazivanje prošlosti $u$ dnevnoj štampi nekih evropskih jezika (in Anali Filološkog fakulteta 10 , Belgrado 1970 , p. 295-334) con un riassunto in tedesco Mittel zur Auslegung der Vergangenheit in der Tagespresse einiger europäischen Sprachen (p. 333-334), nonché Modi di esprimere il passato nella lingua degli storici dei popoli balcanici (in Balcanica V, Belgrado 1974, p. 369-394).

${ }^{3}$ Cfr. Kr. Sandfeld et Fledvig Olsen, Syntaxe roumaine I, Parigi 1936, p. 341; Мнхаило Стевановић, Савремени српскохрватски језик II - Cинтакса ['Mihailo Stevanović, Lingua serbocroata contemporanea II - Sintassi'], Belgrado 1969, p. 643; Блаже Конески, Историја македонског језика ['Blaže Koneski, Storia della lingua macedone'], Belgrado - Skopje 1966, p. 168-169; André Mirabel, La langue grecque moderne, Parigi 1959, p. 298-299.

${ }^{2}$ Cfr. Anastas Dodi, De la valeur du passé composé de l'indicatif en albanais (in Studia Albanica I, VII, Tirand 1970, p. 171-184), che si riferisce anche alle funzioni del passato pluricomposto.

$5 \mathrm{~V}$. Antoine Meillet, Sur la disparition des formes simples nel volume Linguistique historique et linguistique générale I, Parigi 1926.

- La discussione della terminologia esposta comparatamente fa parte del nostro lavoro relativo all'espressione del passato nella stampa quotidiana delle lingue europee (cfr. nota 2).

'Cfr. a questo riguardo Mirko Deanović, Ancora sull'Atlante linguistico balcanico (in Linguistica XII — Mélanges Skerlj, Ljubljana 1972, p. 57-59), che mette in rilievo il bisogno di studiare se si debbano includere in questo atlante lo sloveno e l'ungherese.

${ }^{8}$ In una recensione scritta sul nostro volume citato, $M$. A. Gabinski (in Лимба ши литература молдовеняскэ 2, XVI, Kišinev 1973, p. 74-77) osserva con molta ragione che abbiamo trascurato l'eventuale influenza della lingua turca.

Blaže Koneski, op. cit., p. 148-149.

10 Bucarest, 24 novembre 1973, anno XLIII, No 9701.

11. Belgrado, 9 dicembre 1973, anno LXX. No 21616.

12 Sofia, 18 giugno 1973, anno XLVIr, No 169.

13 Skopje, 3 dicembre 1973 , anno XXX. No 9650.

14 Tirana, 1 settembre 1972 , No 210 (7520).

1529 novembre 1973.

16 29 novembre 1973 .

17 Costantinopoli, 26 luglio 1974, anno 51, No 17955.

18 Traduzioni italiane degli esempi citati restano fedeli alle forme temporali incontrate nelle lingue balcaniche. Questi tempi, dunque, vengono sostituiti da quelli rispettivi italiani, cioè l'imperfetto, il passato remoto e il passato semplice. senza tener conto delle esigenze sintattiche dell'italiano.

10 Bisogna mettere in rilievo che il passato semplice ha perduto terreno in vaste zone del territorio linguistico romeno. Cfr. Gramatica limbii romîne ['Grammatica della lingua romena'], Bucarest 1963, p. 236-240, nonché il nostro volume già citato.

${ }^{20}$ L'imperfetto romeno può riferirsi anche alle azioni momentanee, avendo un'applicazione non estranea delle lingue romanze occidentali. Quest'applicazione dell'imperfetto romeno si può rintracciare cominciando dai primi dorumenti scritti in romeno. Cfr. gli esempi di questo tipo dati nel nostro articolo già citato, relativo alla pubblicistica serbocroata e a quella romena.

21. Traducendo i passati analitici dei verbi serbocroati ne abbiamo segnato l'aspetto, cioè perfettivo (pf.) o imperfettivo (impf.). - I nostri tentativi di vedere come si rispecchia l'aspetto verbale serbocroato nelle lingue romanze hanno dato risultati parziali. Cfr. Cum se reflectă aspectul verbal sîrbocroat in 
limba română? ['Come si rispecchia l'aspetto verbale serbocroato nella lingua romena?'] (in Anale ale Societătii de limba română din Voivodina 2, Zrenjanin 1971 , p. 25-39); nonché Possibilità d'esprimere l'aspetto verbale serbocroato nell'italiano?! (in Italica Belgradensia, in corso di stampa).

2: $\mathrm{Si}$ tratta di un verbo serbocroato biaspettuale, la cui aspettualità viene regolata dal contesto.

${ }_{23}$ In questo caso abbiamo da fare con un verbo biaspettuale, la cui aspettualità non viene precisamente regolata neanche dal contesto.

${ }^{*}$ Si tratta di un passivo del presente che fa le veci anche del passato. Cfr. Ксенија Мнлошевић, Темпорално значење и синтаксичка вредност конструкција 'Cop' у српскохрватском језику ['Ksenija Milošević, Significato temporale e valore sintattico dei costrutti 'Cop' nella lingua serbocroata'] (in Južnoslovenski filolog XXX - Studia linguistica in honorem Michaelis Stevanović, Belgrado 1973 , p. $423-436$ ).

פ5 Cfr. Pavle Ivić, Die serbokroatischen Dialekte, I Band, 'S-Gravenhage 1958, passim; nonché Петар Сладојевић, О значају аориста у српскохрватском језику ['Sull'importanza dell'aoristo nella lingua serbocroata'] (in Južnoslovenski filolog XXI, t. 1-4, Belgrado 1955-56, p. 131-136).

${ }_{26}$ Quanto alle funzioni dei tempi in questione, efr. $\mathrm{C}_{\text {. }}$. Стоянов, Граматика иа български книжовен език ['St. Stojanov, Grammatica della lingua bulgara letteraria'], Sofia 1964 , p. $346-362$. A questo riguardo sono molto istruttivi i testi offerti dal volume: Ст. Гинина, Цв. Николова, Л. Саказова, уџбеник бугарског језика за странце ['St. Ginina, Cv. Nikolova, L. Sakazova, Manuale di lingua bulgara per stranieri'], Sofia 1965, passim.

${ }_{27}$ Cfr. Блаже Конески, Граматика на македонскиот литературен јазик, дел II ['Blaže Koneski, Grammatica della lingua macedone letteraria, parte II'], Skopje 1954, p. 163-170.

${ }_{28}$ Dell'uso dei due tempi in questione c'informa $K$. Cipo, Sintaksa ['Sintassi'], Tirana 1952 , p. $41-42$. Quanto all'uso del passato analitico, rinviamo all'articolo già citato di $\mathrm{A}$. Dodi.

29 Per i tempi greci rinviamo a Andrê Mirambel, op. cit., p. 134-135 e 140.

so Cfr. Muharem Ergin, Türk Dilbilgisi ['Grammatica turca'], Sofia 1967, p. $282-285$.

31 Cfr. Kr. Sandfeld, Linguistique balkanique, p. 160.

32 In questo luogo dobbiamo ringraziare i professori universitari di Belgrado Eros Sequi e Slavoljub Djindjić, nonché il collaboratore all'Accademia delle scienze serba di Belgrado Nikola Rodić di esserci stati sempre a disposizione dandoci preziosi suggerimenti.

\section{Rezime}

\section{ISKAZIVANJE PROŠLOSTI U DNEVNOJ ŠTAMPI BALKANSKIH JEZIKA}

Na osnovu sredstava za iskazivanje prošlosti (a ne i preterita prošlosti, koji nije predmet ovog rada) kojima se služi dnevna štampa (ali ne i drugi jezički pristupi), autor dolazi do saznanja, što ilustruje primerima iz svakog pojedinačnog jezika, da se svi balkanski jezici u ovom pogledu mogu podeliti u dve grupe. Prvu grupu čine rumunski i srpskohrvatski, koji ovaj odnos iskazuju skoro isključivo analitičkim oblicima, tj. složenim perfelitom. Prvi od njih samo retko pribegava imperfektu, a drugi se samo izuzetno služi aoristom (prostim perfektom). Drugu grupu čine ostali balkanski jezici: bugarski, makedonski. albanski i grčki koji, za razliku od prvih, pomenuti odnos iskazuju sintetičkim sredstvima, tj. prostim perfektom (aoristom) i imperfektom, dok složeni perfekat primenjuju samo izuzetno. Sto se tiče turskog, on, kao neindoevropski, pokazuje svoje osobenosti, ali se, kao sintetičan, umnogome uklapa u drugu grupu. 
Idući za odnosom analitičkog i sintetičkog izražavanja, a imajući u vidu procese koji su se odigrali $u$ ovom smislu na širokim evropskim prostranstvima, autor je sklon da veruje kako sintetički način iskazivanja prošlosti na Balkanu predstavlja arhaizam koji se postepeno povlači pred analitičkim izražavanjem ovog odnosa kakav zrači iz Evrope. O tome svedoči najbolje nepostojanje aorista i imperfekta u slovenačkom jeziku kao i u kajkavskom i čakavskom dijalektu srpskohrvatskog jezika.

Nema sumnje da je za očuvanje sintetičkog iskazivanja prošlosti odlučujuću ulogu, na Balkanu, imao grčki jezik (slovenski jezici van Balkana, sem lužičkog, odavno ne znaju ni za aorist ni za imperfekat), dok je turski, unet mnogo kasnije, samo doprineo održavanju postojećeg stanja. 